\title{
Update on Terrestrial Ages of Antarctic Meteorites
}

K.C. Welten, K. Nishiizumi and M.W. Caffee

This article was submitted to $31^{\text {st }}$ Lunar and Planetary Science Conference Houston, $T X$

March 13-17, 2000

\section{January 14, 2000}

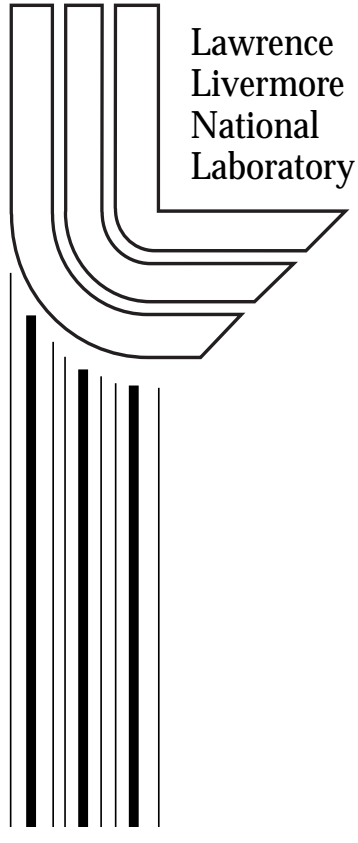




\section{DISCLAIMER}

This document was prepared as an account of work sponsored by an agency of the United States Government. Neither the United States Government nor the University of California nor any of their employees, makes any warranty, express or implied, or assumes any legal liability or responsibility for the accuracy, completeness, or usefulness of any information, apparatus, product, or process disclosed, or represents that its use would not infringe privately owned rights. Reference herein to any specific commercial product, process, or service by trade name, trademark, manufacturer, or otherwise, does not necessarily constitute or imply its endorsement, recommendation, or favoring by the United States Government or the University of California. The views and opinions of authors expressed herein do not necessarily state or reflect those of the United States Government or the University of California, and shall not be used for advertising or product endorsement purposes.

This is a preprint of a paper intended for publication in a journal or proceedings. Since changes may be made before publication, this preprint is made available with the understanding that it will not be cited or reproduced without the permission of the author.

This report has been reproduced directly from the best available copy.

Available to DOE and DOE contractors from the

Office of Scientific and Technical Information

P.O. Box 62, Oak Ridge, TN 37831

Prices available from (423) 576-8401

http:/ / apollo.osti.gov/bridge/

Available to the public from the National Technical Information Service

U.S. Department of Commerce 5285 Port Royal Rd., Springfield, VA 22161 http://www.ntis.gov/

OR

Lawrence Livermore National Laboratory Technical Information Department's Digital Library http://www.llnl.gov/tid/Library.html 
UPDATE ON TERRESTRIAL AGES OF ANTARCTIC METEORITES. K. C. Welten ${ }^{1}$, K. Nishiizumi ${ }^{1}$ and M. W. Caffee ${ }^{2},{ }^{1}$ Space Sciences Laboratory, University of California, Berkeley, CA 94720-7450, USA (e-mail: kcwelten@uclink4.berkeley.edu), ${ }^{2}$ CAMS, Lawrence Livermore National Laboratory, Livermore, CA 94551, USA.

Introduction: Terrestrial ages of Antarctic meteorites are one of the few parameters that will help us to understand the meteorite concentration mechanism on blue-ice fields. Traditionally, terrestrial ages were determined on the basis of ${ }^{36} \mathrm{Cl}$ in the metal phase, which has an uncertainty of about $70 \mathrm{ky}$. For young meteorites $(<40 \mathrm{ky})$, the terrestrial age is usally and most accurately determined using ${ }^{14} \mathrm{C}$ in the stone phase. In recent years two methods have been developed which are independent of shielding effects, the ${ }^{10} \mathrm{Be}^{-{ }^{36}} \mathrm{Cl} /{ }^{10} \mathrm{Be}$ method and the ${ }^{41} \mathrm{Ca} /{ }^{36} \mathrm{Cl}$ method [1,2]. These methods have reduced the typical uncertainties in terrestrial ages by a factor of 2 , to about $30 \mathrm{ky}$. The ${ }^{10} \mathrm{Be}-$ ${ }^{36} \mathrm{Cl} /{ }^{10} \mathrm{Be}$ method is quite dependent on the exposure age, which is unknown for most Antarctic meteorites. We will therefore also attempt to use the relation between ${ }^{26} \mathrm{Al}$ and ${ }^{36} \mathrm{Cl} /{ }^{26} \mathrm{Al}$ to derive a terrestrial age less dependent on the exposure age. We have measured the concentrations of cosmogenic ${ }^{10} \mathrm{Be},{ }^{26} \mathrm{Al}$ and ${ }^{36} \mathrm{Cl}$ in the metal phase of $\sim 70$ Antarctic meteorites, from more than 10 different ice-fields, including many new ones. We will discuss the trends in terrestrial ages of meteorites from different ice-fields.

The three terrestrial age methods discussed above are all based on the metal phase. Some meteorites do not contain metal or the metal has mostly been converted to weathering products [3]. For these meteorites, the stone fraction can be used to determine the terrestrial age, but in recent years, the concern has grown that even Antarctic meteorites are not a closed system with respect to cosmogenic nuclides. For instance, in the case of ${ }^{14} \mathrm{C}$, it has proven important that meteorite finds are treated with phosphoric acid to remove terrestrial carbonate weathering products [4]. It was also shown that the cosmogenic nuclide record can be altered dramatically for extremely weathered chondrites from Roosevelt County, New Mexico [5]. These weathering effects do not only include leaching of ${ }^{36} \mathrm{Cl}$ from the stone fraction, but also a concentration effect of ${ }^{10} \mathrm{Be}$ and ${ }^{26} \mathrm{Al}$, which are retained in the weathering products, whereas major elements, such as $\mathrm{Si}$ and $\mathrm{Mg}$, are lost [4]. Such dramatic weathering effects are not expected for Antarctic meteorites, but it has been speculated that some Antarctic meteorites may be contaminated with meteoric (atmospheric) ${ }^{10} \mathrm{Be}$, absorbed from meltwater during exposure of meteorites on the ice surface [6]. We started some leaching experiments on Antarctic meteorites to evaluate the concerns of pos- sible contamination with meteoric ${ }^{10} \mathrm{Be}$.

Experimental Procedures: For the leaching experiment, we analzyed an exterior and an interior chip of ALH 83100, a $3 \mathrm{~kg} \mathrm{CM} 2$ chondrite. This meteorite was selected because of it low ${ }^{10} \mathrm{Be}$ content of 2.8 $\mathrm{dpm} / \mathrm{kg}$ and its near-absence of metal. Samples of about $100 \mathrm{mg}$ were first leached for $10 \mathrm{~min}$. in an ultrasonic bath with $0.1 \mathrm{~N} \mathrm{HNO}_{3}$, then with $1.5 \mathrm{~N} \mathrm{HNO}_{3}$ in an ultrasonic bath for $30 \mathrm{~min}$. Following each leaching step, the meteorite sample was rinsed with deionized water and ethanol in an ultrasonic bath. For each leaching step, we added about $0.75 \mathrm{mg} \mathrm{Be}$ carrier. After leaching, aliquots were taken (of the solution) for chemical analysis, and the $\mathrm{Be}, \mathrm{Al}$ and $\mathrm{Cl}$ fractions were separated and purified. The concentrations of ${ }^{10} \mathrm{Be}$, ${ }^{26} \mathrm{Al}$ and ${ }^{36} \mathrm{Cl}$ were measured at the LLNL-AMS facility [7].

The ${ }^{26} \mathrm{Al}-{ }^{36} \mathrm{Cl} /{ }^{26} \mathrm{Al}$ Method: We used our existing ${ }^{26} \mathrm{Al}$ and ${ }^{36} \mathrm{Cl}$ data, measured in iron meteorites and in the metal phase of stony and stony-iron meteorite falls as well as data from finds with known terrestrial ages, (e.g. [2]). The combined dataset gives a relatively good correlation $(\mathrm{R}=0.87)$, which shows a little more scatter than the the correlation of ${ }^{36} \mathrm{Cl} /{ }^{10} \mathrm{Be}$ vs. ${ }^{10} \mathrm{Be}$ [8]. The scatter in Fig. 1 is mainly observed for iron and stony-iron meteorites and may be attributed to the contribution of phosphorus to the ${ }^{26} \mathrm{Al}$ production. The best fit polynomial line follows the relation: ${ }^{36} \mathrm{Cl} /{ }^{26} \mathrm{Al}=$ $7.82+0.22 *\left({ }^{26} \mathrm{Al}\right)-0.17 *\left({ }^{26} \mathrm{Al}\right)^{2}$.

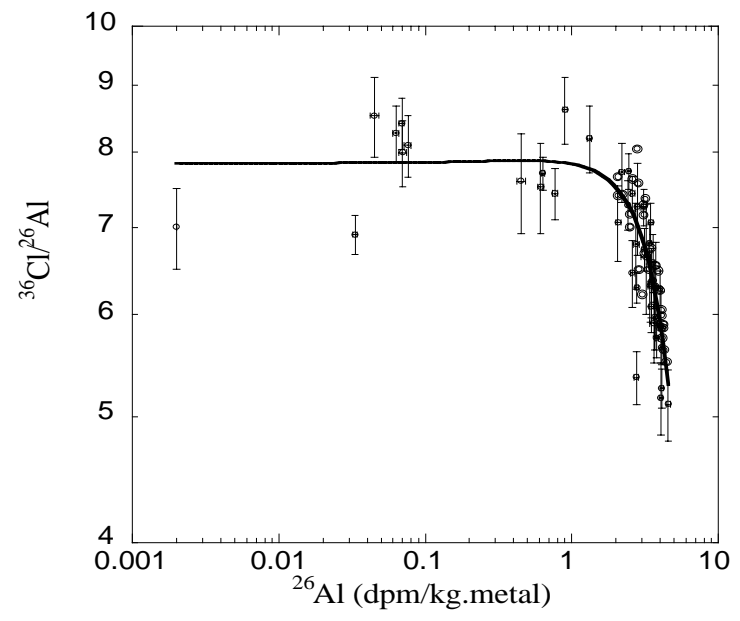

Fig. 1. Aluminium-26 vs. ${ }^{36} \mathrm{Cl} /{ }^{26} \mathrm{Al}$ ratio for iron meteorites and metal phases of stony and stony-iron meteorites. For meteore finds, measured ${ }^{36} \mathrm{Cl}$ and ${ }^{26} \mathrm{Al}$ concentrations were corrected for terrestrial age. 
We will use this relation to determine the terrestrial ages of Antarctic meteorites. In order to get reliable values for ${ }^{26} \mathrm{Al}$ in the metal phase we measured the concentration of $\mathrm{Mg}$ in the dissolved samples by atomic absorption spectroscopy. In this way, we could estimate the silicate contamination and correct for the amount of ${ }^{26} \mathrm{Al}$ from silicates.

Terrestrial Ages: For most Antarctic meteorites, the ${ }^{36} \mathrm{Cl}^{26} \mathrm{Al}$ ages agree well with the ${ }^{36} \mathrm{Cl} /{ }^{10} \mathrm{Be}$ ages. For meteorites with short exposure ages, the ${ }^{36} \mathrm{Cl}^{10} \mathrm{Be}$ ages are lower than the ${ }^{36} \mathrm{Cl}^{26} \mathrm{Al}$ ages. The ${ }^{26} \mathrm{Al} /{ }^{10} \mathrm{Be}$ ratio in the metal phase gives a first estimate of the exposure age, which leads to more consistent terrestrial ages. For 48 out of 67 Antarctic meteorites the terrestrial age is below $100 \mathrm{ky}$ (Fig. 2).

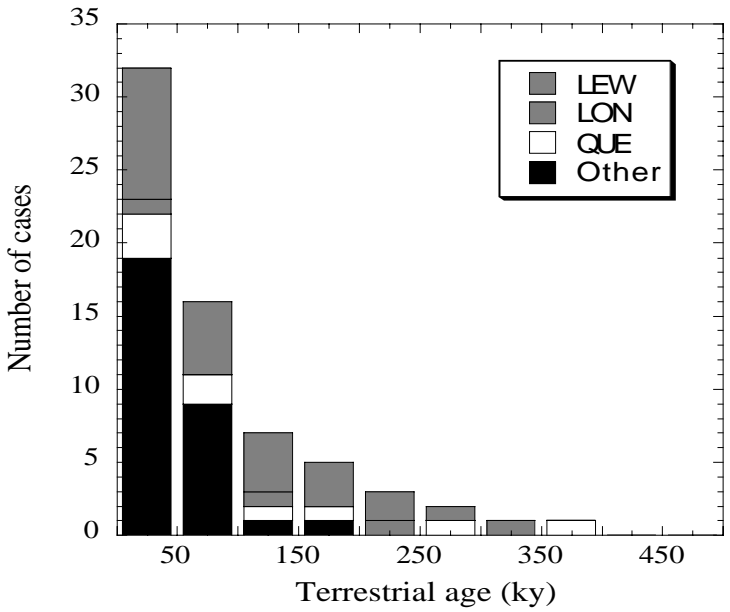

Fig. 2. Terrestrial ages of Antarctic meteorites from Lewis Cliff, Lonewolf Nunatak, Queen Alexandra Range and other stranding areas.

Meteorites older than $200 \mathrm{ky}$ are only found on the Lewis Cliff (LEW), the Foggy Bottom (QUE) and the Lonewolf Nunatak (LON) stranding areas. The high terrestrial ages of LEW meteorites confirm earlier measurements $[6,9]$. The high terrestrial ages (up to $400 \mathrm{ky}$ ) of QUE meteorites are not surprising, since this stranding area is close to the LEW area and in the past decade several thousand meteorites have been recovered from the moraines and ice-fields near the Queen Alexandra Range. However, the high terrestrial ages of the LON meteorites ( 3 out of 4 are older than $100 \mathrm{ky}$ ), are most interesting, since so far only 10 meteorites were recovered from this stranding area, which is located about halfway between the Allan Hills and Lewis Cliff stranding areas. The high terrestrial ages and the fact that all of these meteorites were quite large (between $100 \mathrm{~g}$ and $10 \mathrm{~kg}$ ), suggests that many more smaller meteorites may be recovered from this relatively new stranding area, which was visited only once, in 1994.
Leaching experiments. The first preliminary results of the leaching experiment are shown in Table 1. The data show a slight excess of ${ }^{10} \mathrm{Be}$ in all leach fractions, relative to the bulk value of $2.8 \mathrm{dpm} / \mathrm{kg}$. However, this may be due to leaching of ${ }^{10} \mathrm{Be}$ from small silicate grains, which did not completely dissolve, so it is not necessarily an indication of meteoric ${ }^{10} \mathrm{Be}$. This is confirmed by the fact that the leach fractions from the exterior sample do not show higher ${ }^{10} \mathrm{Be}$ than those from the interior sample. AMS measurements of ${ }^{26} \mathrm{Al}$ and ${ }^{36} \mathrm{Cl}$ are in progress, whereas additional leaching experiments with milder reagents and other meteorites are being planned.

Acknowledgments. This work was supported by NASA grant NAG5-4992, NSF grant OPP-9316272 and was performed under the auspicies of the D.O.E. by LLNL under contract W-7405-ENG-48.

References: [1] Nishiizumi K. and Caffee M. W. (1998) Meteoritics \& Planet. Sci., 33, A117. [2] Lavielle B. et al. (1999) Earth Planet. Sci., 107, 93-104. [3] Welten K. C. (1999) Meteoritics \& Planet. Sci., 34, 259-270. [4] Bland P. A. et al. (1998) Geochim. Cosmochim. Acta 62, 3169-3184. [5] Welten K. C. et al. (2000) LPI Tech. Rpt. (in press), [6] Welten K. C. et al. (1999) Meteoritics \& Planet. Sci., 34, 559-569. [7] Davis J. C. et al. (1990) Nucl. Instr. Meth. B52, 269-272. [8] Nishiizumi K. et al. (1997) Meteoritics \& Planet. Sci., 32, A100. [9] Nishiizumi K. (1995) LPI Tech. Rpt. 95-02, 53-55.

Table 1. Concentrations of ${ }^{10} \mathrm{Be}$ in a bulk sample as well as in leaching fractions of interior and exterior samples of ALH 83100.

\begin{tabular}{lccc}
\hline $\begin{array}{l}\text { Sample } \\
\text { ALH83100 }\end{array}$ & $\begin{array}{c}\text { Leach } \\
\text { solution }\end{array}$ & $\begin{array}{c}\text { Dissolved } \\
(\mathrm{mg})\end{array}$ & $\begin{array}{c}{ }^{10} \mathrm{Be} \\
(\mathrm{dpm} / \mathrm{kg})\end{array}$ \\
\hline$\# 191$ (ext.) & $0.1 \mathrm{~N} \mathrm{HNO}_{3}$ & 12 & $3.5 \pm 0.1$ \\
$\# 191$ (ext.) & $1.5 \mathrm{~N} \mathrm{HNO}_{3}$ & 60 & $3.2 \pm 0.1$ \\
$\# 192$ (int.) & $0.1 \mathrm{~N} \mathrm{HNO}_{3}$ & 18 & $3.6 \pm 0.1$ \\
$\# 192$ (int.) & $1.5 \mathrm{NNO}_{3}$ & 35 & $4.0 \pm 0.1$ \\
$\# 76$ & bulk & 926 & $2.8 \pm 0.1$ \\
\hline
\end{tabular}

